\title{
Erectile dysfunction in a cohort of HIV-infected male patients
}

\author{
Narcis Chirca ${ }^{1,2^{*}}$, Anca Streinu-Cercel ${ }^{2,3}$, Viorel Jinga ${ }^{1,2}$, Adrian Streinu-Cercel ${ }^{2,3}$ \\ From The 10th Edition of the Scientific Days of the National Institute for Infectious Diseases "Prof Dr Matei Bals" \\ Bucharest, Romania. 15-17 October 2014
}

\section{Background}

The advent of antiretroviral therapy has transformed HIV infection into a manageable chronic disease, where improving the quality of life of HIV-infected patients has become one of the main focus points for physicians. The aim of our study was to evaluate the prevalence of erectile dysfunction and testosterone deficiency in a cohort of HIV-infected patients monitored in the National Institute for Infectious Diseases "Prof. Dr. Matei Balş" Bucharest, from May 2014 to June 2014.

\section{Methods}

We evaluated a cohort of HIV-infected male patients. They completed a questionnaire to evaluate erectile dysfunction, based on the International Index of Erectile Function - IIEF (maximum score 30 for questions $1,2,3,4,5,15)$. Total testosterone was dosed in a subset of patients reporting erectile dysfunction (mild and moderate or severe) considering normal values $>10 \mathrm{nmol} / \mathrm{L}$. Five patients refused the test.

\section{Results}

42 patients completed the questionnaire; they had ages between 23 and 69 years (mean age 36.8), 38 of them (90.4\%) receiving antiretroviral therapy. 15 patients had a degree of erectile dysfunction (35.7\% of total) and 2 patients had had no sexual activity in the last month: 12 patients had mild erectile dysfunction (score between 19-24), 2 patients had mild to moderate erectile dysfunction (score between 13-18), 1 patient had moderate erectile dysfunction (score between 7-12). Total testosterone was tested for 3 patients, 5 refused the test; all tests revealed normal values $(>20 \mathrm{nmol} / \mathrm{L})$.

\footnotetext{
* Correspondence: chirca_narcis@yahoo.com

"Urology Department, Clinical Urology Hospital "Prof. Dr. Th Burghele" Bucharest, Romania

Full list of author information is available at the end of the article
}

\section{Conclusion}

This study showed that erectile dysfunction is highly prevalent, $35.7 \%$ of HIV-infected male patients have reported erectile problems.

\section{Acknowledgement}

This paper is supported by Sectoral Operational Programme Human Resources Development (SOPHRD), financed from the European Social Fund and by the Romanian Government under the contract number POSDRU/ 159/1.5/S/137390.

\section{Authors' details}

"Urology Department, Clinical Urology Hospital "Prof. Dr. Th Burghele" Bucharest, Romania. ${ }^{2}$ Carol Davila University of Medicine and Pharmacy, Bucharest, Romania. ${ }^{3}$ National Institute for Infectious Diseases "Prof. Dr. Matei Balş", Bucharest, Romania.

Published: 15 October 2014

\section{doi:10.1186/1471-2334-14-S7-P31}

Cite this article as: Chirca et al:: Erectile dysfunction in a cohort of HIV-infected male patients. BMC Infectious Diseases 2014 14(Suppl 7):P31.

\author{
Submit your next manuscript to BioMed Central \\ and take full advantage of: \\ - Convenient online submission \\ - Thorough peer review \\ - No space constraints or color figure charges \\ - Immediate publication on acceptance \\ - Inclusion in PubMed, CAS, Scopus and Google Scholar \\ - Research which is freely available for redistribution \\ Submit your manuscript at \\ www.biomedcentral.com/submit
}

() Biomed Central

(c) 2014 Chirca et al; licensee BioMed Central Ltd. This is an Open Access article distributed under the terms of the Creative Commons Attribution License (http://creativecommons.org/licenses/by/4.0), which permits unrestricted use, distribution, and reproduction in any medium, provided the original work is properly cited. The Creative Commons Public Domain Dedication waiver (http://creativecommons.org/publicdomain/zero/1.0/) applies to the data made available in this article, unless otherwise stated. 